\title{
Influence of the inorganic phase concentration and geometry on the viscoelastic properties of latex coatings through the glass-transition
}

\author{
Eric W. S. Hagan ${ }^{\mathrm{a}, \mathrm{b}^{*}}$, Maria N. Charalambides ${ }^{\mathrm{b}}$, Christina R. T. Young ${ }^{\mathrm{c}}$, Thomas J. S. \\ Learner ${ }^{\mathrm{d}}$, Stephen Hackney ${ }^{\mathrm{a}}$ \\ ${ }^{a}$ Conservation Department, Tate, Millbank, London, SW1P 4RG, UK \\ E: stephen.hackney@tate.org.uk \\ ${ }^{\mathrm{b}}$ Department of Mechanical Engineering, Imperial College London, South Kensington Campus, London, SW7 2AZ, UK \\ E: $\underline{\text { m.charalambides@imperial.ac.uk }}$ \\ ${ }^{c}$ Department of Conservation \& Technology, The Courtauld Institute of Art, Sommerset House, Strand, London, WC2R 0RN, UK \\ E: christina.young@courtauld.ac.uk \\ ${ }^{\mathrm{d}}$ Getty Conservation Institute, 1200 Getty Center Drive, Suite 700, Los Angeles, CA, 90049-1684, USA \\ E: tlearner@getty.edu \\ "corresponding author; current address: \\ Canadian Conservation Institute 1030 Innes Rd. Ottawa, ON K1B 4S7 Canada \\ T: +1 (613) 998-3721 x224 \\ E: eric.hagan@pch.gc.ca
}

Keywords : latex; coating; viscoelastic; composite;

\begin{abstract}
The mechanical properties of artists' acrylic (latex) paint films containing different volume fractions of $\mathrm{TiO}_{2}, \mathrm{CaCO}_{3}$ and kaolin were measured in uniaxial tension over a broad range of temperatures and crosshead speeds. Young's modulus results in the glassy region were first compared with several micromechanics theories for particle-filled composites containing elastic phases. It was found that the Mori-Tanaka theory slightly under-predicted the modulus enhancement, while the Lielens approach provided the most accurate results. A nonlinear viscoelastic material model involving a Prony series and the neo-Hookean hyperelastic function was used to represent the tensile data up to relatively small strains of a few percent. From the experimental data, the material model was calibrated and the required parameters were determined. The derived parameters were then used to re-construct relaxation modulus plots, which were compared with the approximations given by Clements and Mas for the viscoelastic Mori-Tanaka theory in the time-domain. It was found that the experimentally observed modulus enhancement was much stronger than the predicted values in the rubbery region. Mechanisms such as constrained polymer at the inorganic particle interface, and the possible formation of a percolation network are discussed.
\end{abstract}

\section{Introduction}

Since their commercial appearance in the early 1950's, latex paints have become increasingly common. Their properties are easily tailored to a variety of applications and the use of an aqueous carrier phase offers lower volatile organic compounds (VOCs) than oil-based products. The chemical durability, flexibility and low yellowing of acrylic copolymers have made them especially suitable as a binder for artist paints, which are the focus of this work.

The first acrylic paint formulations were comprised of a random copolymer of ethyl acrylate (EA) and methyl methacrylate (MMA). Early technical latexes for coatings (acrylic type) 
contained approximately $62-64 \%$ EA, $1-2 \%$ acrylic acid, with the remaining hardening monomer as MMA. The monomer ratio is important for achieving a copolymer with a glasstransition, $T_{g}$, slightly below ambient temperature. This ensures proper film formation and optimal mechanical properties of the dried paint. The small acrylic acid component is included for latex stability, gloss, and pigment wetting [1]. During the 1980's, artist paint manufacturers began using $n$-butyl acrylate ( $n \mathrm{BA})$ monomers in place of EA [2]. The lower $T_{g}$ of poly $(n \mathrm{BA})$ suggests that a slightly lower fraction of $n \mathrm{BA}$ is required compared to EA. It is also common for the molecular weight of the copolymer to be very large for coatings applications $\left(\sim 10^{6} \mathrm{~g} / \mathrm{mol}\right)$ [3], which leads to a high-degree of entanglement in the matrix of a coalesced film.

Latex film formation has been widely investigated [4, 5] and is often described in several stages: (1) convergence of particles as water evaporates; (2) particle ordering and packing; and (3) inter-diffusion. Coating formulations contain many additives to achieve stability with suitable properties before and after coalescence. Common ingredients include surfactants, dispersants, thickeners, defoamers, biocides and a variety of other materials. Acrylic formulations typically require a large quantity of surfactant to disperse the small $1-2 \mu \mathrm{m}$ diameter latex particles in the aqueous carrier phase. After drying, the low molecular weight surfactants may migrate to the surfaces of the film or the inorganic particles. They can also become trapped at the surfaces of the latex particles and impede coalescence [6]. The ingredients of primary consideration in the forthcoming discussion are the polymeric binder and the inorganic particles since they contribute most significantly to the final film properties after drying.

An understanding of the tensile properties of paint films is important for manufacturers as they relate to general performance characteristics. This information is also valuable for museums and galleries where the response of paintings under different environments is of concern. Large amounts of energy are expended to maintain temperature and humidity conditions in museums, with limited material data available. Prior studies have investigated the properties of neat latex films [7-10] and artists' acrylic paints [11-13] in tension. The present work provides a broader overview of the influencing parameters by using a common poly $(n \mathrm{BA} / \mathrm{MMA})$ binder in custom formulated latex paints. Factors under consideration include temperature, strain-rate, inorganic volume fraction, and particle geometry/orientation. The results from tensile data at small strains are also used to examine micromechanics theories above and below the glass-transition. A brief review of micromechanics models is given next for predicting the modulus enhancement of particle filled composites. This is followed by details of the experimental methods, and a discussion of the results in relation to theoretical predictions.

\subsection{Micromechanics models}

Numerous analytical models are available in the literature to describe the Young's modulus enhancement, $E^{*} / E^{m}$, in particle-filled composites when each phase is elastic [14]. Two wellknown theories are the self-consistent model described by Hill [15], and the Mori-Tanaka [16] equations modified for composites by Tandon and Weng [17, 18]. These predictions rely on the concept of average strain in each phase and use Eshelby's tensor, E $[19,20]$ to account for particle geometry. A brief overview of the equations is presented here. Superscripts $*, f$, and $m$ are used to denote composite, particle and matrix respectively.

The general equation for determining the stiffness tensor of a composite [14] is 


$$
\mathbf{C}^{*}=\mathbf{C}^{m}+c^{f}\left(\mathbf{C}^{f}-\mathbf{C}^{m}\right) \mathbf{A}
$$

where

$$
\mathbf{A}=\hat{\mathbf{A}}\left[\left(1-c^{f}\right) \mathbf{I}+c^{f} \hat{\mathbf{A}}\right]^{1}
$$

The calculation in Equation 1 depends on the stiffness tensor of the matrix and filler $\left(\mathbf{C}^{f}, \mathbf{C}^{\mathbf{m}}\right)$, the filler volume fraction $\left(c^{f}\right)$, and the strain enhancement tensors $(\mathbf{A}, \hat{\mathbf{A}})$. These strain enhancement tensors are defined by the ratios

$$
\begin{aligned}
\hat{\mathbf{A}} & =\overline{\boldsymbol{\varepsilon}}^{f} / \bar{\varepsilon}^{m} \\
\mathbf{A} & =\overline{\boldsymbol{\varepsilon}}^{f} / \bar{\varepsilon}
\end{aligned}
$$

where $\bar{\varepsilon}^{f}, \bar{\varepsilon}^{m}, \bar{\varepsilon}$ are the average strains in the filler, matrix and composite respectively.

In the Mori-Tanaka method, Equations 1 and 2 are solved according to:

$$
\hat{\mathbf{A}}=\left[\mathbf{I}+\mathbf{E S}^{m}\left(\mathbf{C}^{f}-\mathbf{C}^{m}\right)\right]^{1}
$$

where $\mathbf{I}, \mathbf{E}$, and $\mathbf{S}^{\boldsymbol{m}}$ are the unity matrix, Eshelby tensor, and compliance tensor $\left(\mathbf{S}=\mathbf{C}^{-1}\right)$ respectively. Expressions for the components of Eshelby's tensor in terms of the matrix Poisson's ratio, $v^{\mathrm{m}}$, and the aspect ratio, $\beta$, of spheroidal inclusions can be found in [18]. The aspect ratio is defined here as the length along the major axis of a spheroid divided by the diameter along the minor axis. Spheres, oblate spheroids and prolate spheroids correspond to $\beta$ values of one, smaller than one and larger than one respectively.

More recently, Lielens [21] proposed a modified theory for improved accuracy at high filler fractions after noting that the Mori-Tanaka method under-predicts modulus enhancement in this region. The Lielens [14, 21] approach involves first determining the upper and lower bounds for $\hat{\mathbf{A}}$ by using the filler and matrix as the reference material in Eshelby's tensor. This gives

$$
\begin{aligned}
& \hat{\mathbf{A}}^{\text {upper }}=\left[\mathbf{I}+\mathbf{E}^{f} \mathbf{S}^{f}\left(\mathbf{C}^{m}-\mathbf{C}^{f}\right)\right]^{1} \\
& \hat{\mathbf{A}}^{\text {lower }}=\left[\mathbf{I}+\mathbf{E}^{m} \mathbf{S}^{m}\left(\mathbf{C}^{f}-\mathbf{C}^{m}\right)\right]^{1}
\end{aligned}
$$

from which $\hat{\mathbf{A}}$ is interpolated between the bounds as

$$
\hat{\mathbf{A}}=\left\{\left(1-f_{L}\right)\left[\hat{\mathbf{A}}^{\text {lower }}\right]^{1}+f_{L}\left[\hat{\mathbf{A}}^{\text {upper }}\right]^{1}\right\}^{-1}
$$

using

$$
f_{L}=\frac{c^{f}+\left(c^{f}\right)^{2}}{2}
$$

The $f_{L}$ parameter is designed to weigh $\hat{\mathbf{A}}$ strongly towards the lower bound at low volume fractions, and give preference to the upper bound at high volume fractions. Note that the 
tensors $\mathbf{E}^{f}$ and $\mathbf{E}^{m}$ are calculated using the Poisson's ratio of the filler and the matrix respectively.

The tensor calculations described in Equation 1 may be used to determine $\mathbf{C}^{*}$ for a particlefilled composite containing spherical or aligned non-spherical particles. Van Es [22] gives a simple procedure for determining the modulus of a composite with random oriented particles from the properties of a transversely isotropic composite. Expressions from the randomising method of Van Es for the composite Young's modulus are

$$
\begin{array}{ll}
E_{2 D}^{*}=0.375 E_{11}+0.625 E_{22} & \text { (fibre, random orientation in - plane only) } \\
E_{3 D}^{*}=0.184 E_{11}+0.816 E_{22} & \text { (fibre, 3D random orientation) } \\
E_{3 D}^{*}=0.49 E_{11}+0.51 E_{22} & \text { (disc, 3D random orientation) }
\end{array}
$$

for fibre $(\beta>1)$ and $\operatorname{disc}(\beta<1)$ shaped particles. The parameters $E_{11}$ and $E_{22}$ are the longitudinal and transverse Young's moduli respectively, which may be calculated from any of the micromechanics models outlined in this section.

Two semi-empirical methods commonly used for predicting the modulii of particle-filled composites are the Halpin-Tsai [23, 24] and Nielsen equations [25, 26]. The Halpin-Tsai method for a matrix containing short fibers is:

$$
\frac{E^{*}}{E^{m}}=\frac{1+\left(\frac{E^{f} / E^{m}-1}{E^{f} / E^{m}+\zeta}\right) \zeta c^{f}}{1-\left(\frac{E^{f} / E^{m}-1}{E^{f} / E^{m}+\zeta}\right) c^{f}}
$$

The shape factor parameter, $\zeta$, accounts for the geometry of the filler and has a value of $\zeta=2$ for spherical particles [23]. The approach offered by Nielsen $[25,26]$ is slightly different in that the maximum packing fraction, $\phi_{m}$, of the filler particles is taken into consideration. The Young's modulus enhancement is given by:

$$
\frac{E^{*}}{E^{m}}=\frac{1+\left(k_{E}-1\right) \eta c^{f}}{1-\eta \psi c^{f}}
$$

with $\eta$ and $\psi$ defined as:

$$
\begin{aligned}
& \eta=\frac{E^{f} / E^{m}-1}{E^{f} / E^{m}+k_{E}-1} \\
& \psi=1+\left(\frac{1-\phi_{m}}{\phi_{m}{ }^{2}}\right) c^{f}
\end{aligned}
$$

The Einstein coefficient, $k_{E}$, has a value of 2.5 for an incompressible matrix $\left(v^{m}=0.5\right)$, and its value drops to $k_{E}=2.17$ for $v^{m}=0.35$. For hexagonal, close-packed, spheres the maximum packing fraction is $\phi_{m}=0.74$ [26].

For viscoelastic phases, the above micromechanics models directly apply in the laplacetransformed domain by means of the correspondence principle. Behaviour of this type is discussed in Section 5 with the experimental results through the glass-transition. 


\section{Experimental}

Latex formulations based on a poly(butyl acrylate-co-methyl methacrylate) binder were provided by Golden Artist Colors. The resin was stated to have a $T_{g}$ of $16^{\circ} \mathrm{C}$; however, a value of $10^{\circ} \mathrm{C}$ was measured by differential scanning calorimetry (DSC) [6]. It is expected that low molecular weight additives caused a slight depression of glass-transition temperature. The custom materials included a latex formulation with no inorganic particles present, and the same latex with high concentrations of $\mathrm{TiO}_{2}$ (rutile), $\mathrm{CaCO}_{3}$ (aragonite), and kaolin (calcined) individually. The three formulations with inorganic particles were diluted with additional latex in order to provide several volume fractions in the dried films. The final volume fractions were as follows:
a. $0.06,0.13,0.20,0.25,0.32$, and $0.38 \mathrm{TiO}_{2}$
b. $0.07,0.14,0.22$, and 0.28 kaolin
c. $0.08,0.16,0.24,0.30$, and $0.38 \mathrm{CaCO}_{3}$

Paint films were cast on thin polyester sheets one year in advance of testing to provide wellcoalesced films. The substrate was removed from the films one day prior to testing and specimens were cut to rectangular dimensions of $60 \mathrm{~mm} \times 6 \mathrm{~mm}$ with thickness values in the range of $0.15-0.2 \mathrm{~mm}$. Paper tabs were then bonded to the ends with a cyanoacrylate adhesive leaving a $40 \mathrm{~mm}$ gauge length. The purpose of this step was to minimise slippage and reduce stress induced by the gripping pressure. The fully prepared specimens were placed overnight in small enclosures with silica gel buffering at $50 \%$ relative humidity $(\mathrm{RH})$ to control equilibrium moisture content.

An Instron (model 4301) universal testing machine fitted with an environmental enclosure [27] and a $100 \mathrm{~N}$ load cell was used for tensile tests at five temperatures $(-10,0,10,20$, and $30^{\circ} \mathrm{C}$ ) with relative humidity controlled at $50 \%$ for $T \geq 10^{\circ} \mathrm{C}$. The tests were performed along the casting direction at constant crosshead speeds of $0.05,0.5,5$, and $50 \mathrm{~mm} / \mathrm{min}$ for each temperature, giving a total of 20 test conditions for a single formulation. This set of experimental conditions was applied to the pure latex, three concentrations of $\mathrm{TiO}_{2}$, two concentrations of kaolin and a single concentration of $\mathrm{CaCO}_{3}$. Films with a larger range of volume fractions were tested in the glassy region $\left(5 \mathrm{~mm} / \mathrm{min}\right.$ at $\left.-10^{\circ} \mathrm{C}\right)$ in order to compare modulus data with elastic micromechanics theories. The experiments were relatively fast in the glassy region; therefore, more samples were tested at the lowest temperature. In this latter set of experiments, the tensile tests were conducted across as well as along the casting direction in order to estimate the orientation of the particles in the films.

A stress relaxation experiment was also performed for the binder latex at $20^{\circ} \mathrm{C}, 50 \% \mathrm{RH}$. The sample was extended at $5 \mathrm{~mm} / \mathrm{min}$ to a strain of 0.02 , and the strain was subsequently held constant for a period of 10 minutes.

Due to the very large amount of tests that were performed, the strain was calculated from the displacement recorded directly from the tensile testing machine. The accuracy of this method was confirmed by performing a few tests at both the glassy and rubbery regions where the displacement was measured optically [27].

Dynamic mechanical analysis (DMA) was performed with a TA Instruments model Q800. Experiments were run in tension mode at $1 \mathrm{~Hz}$ with a preload of $0.1 \mathrm{~N}, 0.1 \%$ dynamic strain and $125 \%$ force tracking (static/dynamic). Samples were at an increased age of four years and several $0.15 \mathrm{~mm}$ thick specimens were prepared with a gauge length of $7.5 \mathrm{~mm}$ and width of 
$6 \mathrm{~mm}$. Relative humidity was not controlled during these experiments; however, ambient conditions in the laboratory were at $\sim 30 \% \mathrm{RH}$.

In order to compare modulus data with micromechanics theories it is necessary to determine the aspect ratio, $\beta$, of the inorganic particles and the elastic properties of each phase. Figure 1 shows scanning electron microscopy (SEM) images of each inorganic material. The $\mathrm{TiO}_{2}$ particles are nearly spherical with a nominal diameter of $\sim 300 \mathrm{~nm}$. The image of kaolin shows a wide particle size distribution with an aspect ratio of the larger particles estimated as $\beta \approx 0.1$. Calcium carbonate (aragonite) fibres in Figure 1c have an aspect ratio of approximately four $(\beta=4)$.

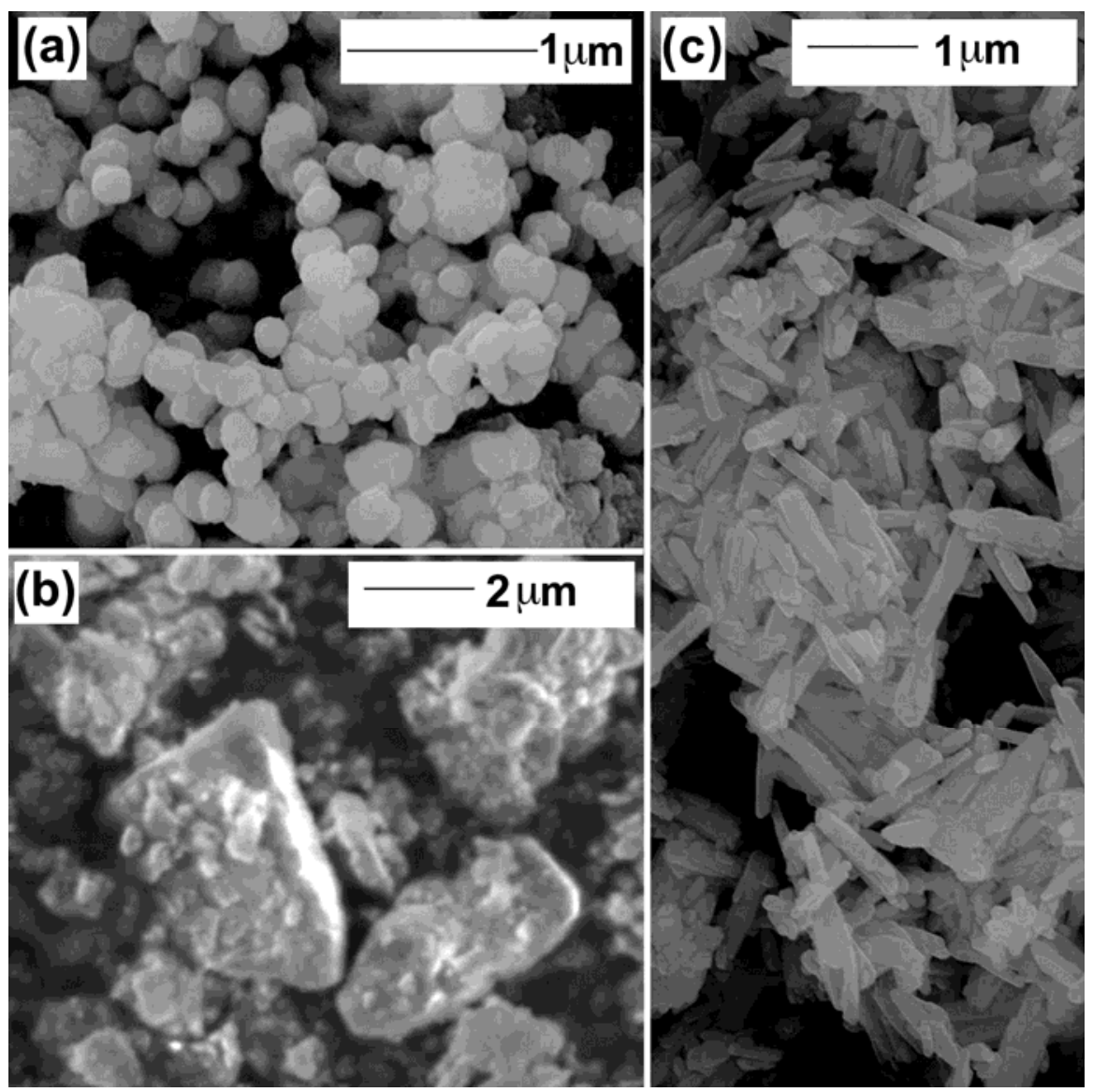

Figure 1. SEM images of inorganic particles: a. $\mathrm{TiO}_{2}$; b. kaolin; c. $\mathrm{CaCO}_{3}$.

The mechanical properties of the three fillers were obtained from literature [28, 29]. Table 1 gives literature values for the bulk modulus, $K$, and shear modulus, $\mu$, along with the calculated Young's modulus, $E$, and Poisson's ratio, $v$, (assuming isotropy). The Young's modulus of the pure BA/MMA latex in the glassy region measured in this work at $5 \mathrm{~mm} / \mathrm{min}$, $-10^{\circ} \mathrm{C}$ (see Section 4) is also provided for comparison. It is apparent that a combination of any of the inorganic materials with the latex matrix will result in $E^{f}$ being about one to two orders of magnitude larger than $E^{m}$. Finally, the Poisson's ratio of the matrix, $v^{m}$, was assumed to be 0.35 in the glassy region [30] and 0.5 (incompressible) in the rubbery region. 
Table 1. Elastic constants for inorganic particles from Bass [29] and Wang et al [28] and experimental values for the glassy latex $\left(E\right.$ taken at $\left.-10^{\circ} \mathrm{C}, 5 \mathrm{~mm} / \mathrm{min}\right)$.

\begin{tabular}{lcccl}
\hline Material & $K(\mathrm{GPa})$ & $\mu(\mathrm{GPa})$ & $E(\mathrm{GPa})$ & $\nu$ \\
\hline $\mathrm{TiO}_{2}{ }^{\mathrm{a}}$ & 216 & 112 & 287 & 0.278 \\
$\mathrm{CaCO}_{3}{ }^{\mathrm{a}}$ (aragonite) & 46.9 & 38.5 & 91 & 0.178 \\
$\mathrm{Kaolinite} \mathrm{(poorly} \mathrm{crystallized)}^{\mathrm{b}}$ & 45.2 & 22.1 & 57 & 0.290 \\
$\mathrm{BA} / \mathrm{MMA}$ Latex $\left(5 \mathrm{~mm} / \mathrm{min}, 10{ }^{\circ} \mathrm{C}\right)$ & 1.66 & 0.53 & 1.44 & 0.35 \\
\hline
\end{tabular}

${ }^{\mathrm{a}}$ Elastic constants for inorganic particles from Bass [29].

${ }^{\mathrm{b}}$ Elastic constants for inorganic particles from Wang et al. [28].

\section{Results and Discussion}

\subsection{Modulus Enhancement in the Glassy Region}

In this section, the experimental results in the glassy region, i.e. data collected at $5 \mathrm{~mm} / \mathrm{min}$, $10^{\circ} \mathrm{C}$, are presented with elastic micromechanics theories. In Figure 2a, the modulus enhancement is compared between filler types for the films tested in the longitudinal (along casting) and transverse (perpendicular to casting) directions. All moduli were calculated using the $0.5 \%$ secant rule since the stress-strain curves were highly non-linear and an initial straight portion was not clearly distinguishable over the range of test conditions. It is immediately apparent that the sample preparation method resulted in some alignment of the non-spherical particles. Films tested in both directions with $\mathrm{TiO}_{2}$ and those in the transverse direction with $\mathrm{CaCO}_{3}$ were similar and they showed the lowest modulus enhancement. The latter agrees with micromechanics models for aligned spheroid particles. It has been shown for these models that enhancement in directions normal to the major axis of aligned fibres is similar to that of spherical particles [31]. That is, the Young's modulus of a composite containing aligned fibres is relatively insensitive to aspect ratio in the transverse direction and a minimum value is obtained. The highest enhancement was observed for the films containing kaolin in the long direction, followed by films with kaolin (trans) and $\mathrm{CaCO}_{3}$ (long).

Figure $2 \mathrm{~b}$ shows the $\mathrm{TiO}_{2}$ data compared with several micromechanics theories that are applicable to spherical particles embedded in an elastic matrix. The Mori-Tanaka curve is slightly lower than the experimental values at moderate to high volume fractions, while the Halpin-Tsai equation is slightly high overall. The best fits for these data are observed by the Lielens model and the Nielsen equation, using a maximum packing fraction of $\phi_{m}=0.74$ for the latter. The Lielens model was also found to be the most accurate by Stapountzi et al [31], based on studies on alumina trihydrate reinforced poly(methyl methacrylate) composites for volume fractions of 33 to $49 \%$. 

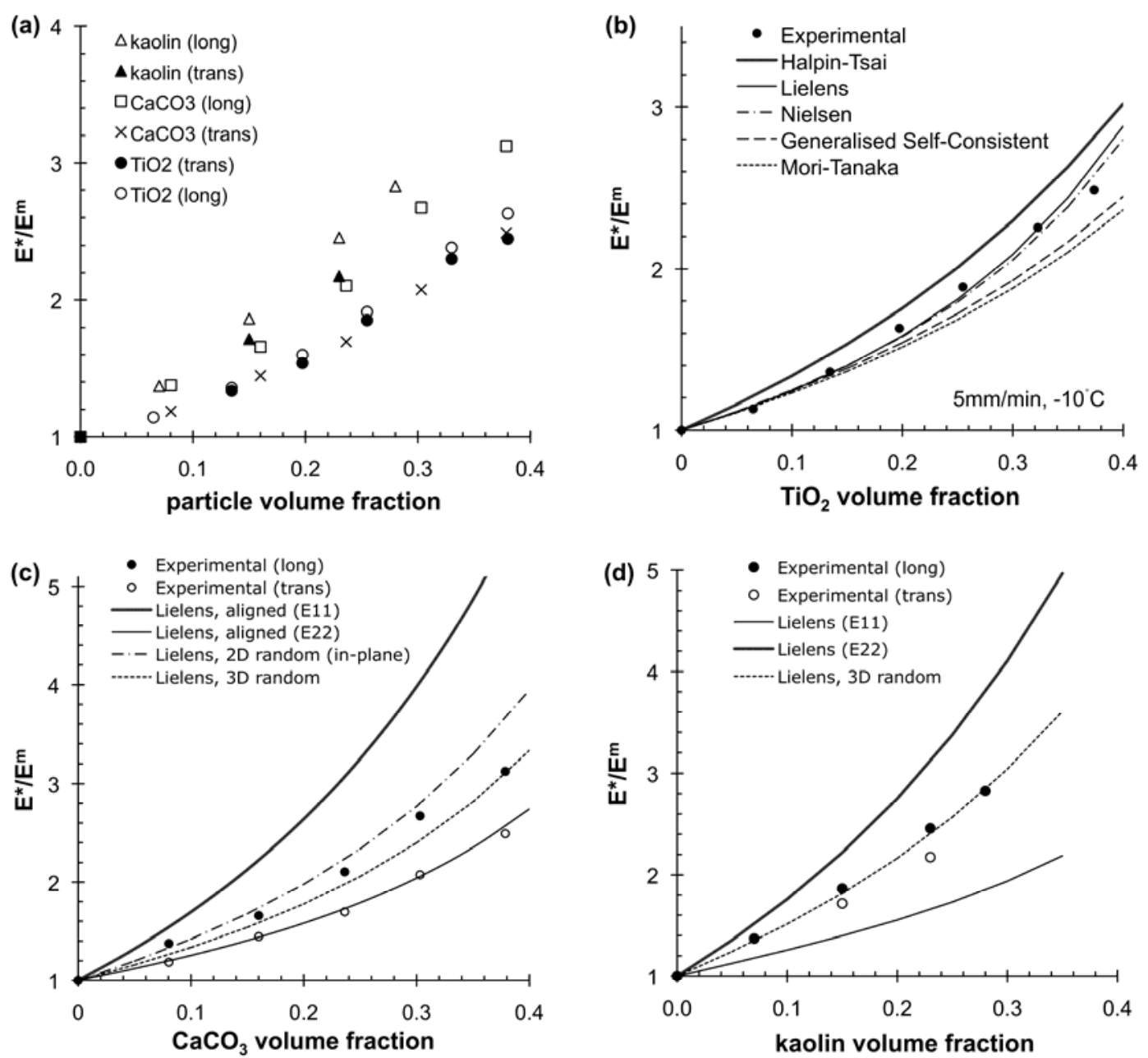

Figure 2. Young's modulus enhancement in the glassy region $\left(5 \mathrm{~mm} / \mathrm{min},-10^{\circ} \mathrm{C}\right)$ : a. Experimental for three particle types; b. $\mathrm{TiO}_{2}$ data and several models; c. $\mathrm{CaCO}_{3}$ data and Lielens theory; d. kaolin data and Lielens theory. $v^{m}=0.35$ and $\phi_{m}=0.74$ where appropriate.

The Lielens model is also compared to data from the films with kaolin and $\mathrm{CaCO}_{3}$ since it is applicable for non-spherical particles. Figure $2 \mathrm{c}$ shows data from the latex films containing $\mathrm{CaCO}_{3}$ plotted with the theory for unidirectional aligned particles, 2D random alignment, and $3 \mathrm{D}$ random alignment (Eq. 8). It is clear that the trans data agree very well with the $E_{22}$ values whereas the long data agree reasonably well with the predictions for $2 \mathrm{D}$ random orientation. This suggests that the particles are 2D randomised within a plane through the film thickness and longitudinal axes. The short $\mathrm{CaCO}_{3}$ fibers possibly became aligned when the wet paint was dragged in the long direction and then tilted in the thickness direction as the film dried (Fig. 3).

The results for the latex with kaolin particles in Figure $2 d$ are more difficult to interpret since a large particle size and shape distribution was observed in the SEM images, and it was only possible to estimate the aspect ratio of the larger particles. Two scenarios are possible for the microstructure of these films. The first possibility is that the particles are primarily 3D randomised and the aspect ratio estimate is widely applicable to the distribution of particles. This theory holds since the curve for the $3 \mathrm{D}$ random particles fits through the data points for the films tested in the long and trans directions. An alternate possibility is that the aspect ratio estimate was too high and the platelet particles are actually 2D oriented within the long-trans plane of the film as a result of the preparation method. In theory, this would give a similar modulus (equal to $E_{22}$ ) in the long and trans directions and a low modulus in the thickness 
direction $\left(E_{11}\right)$. Unfortunately, it was not practical to obtain modulus data in the thickness direction in order to clarify the microstructure of these films.

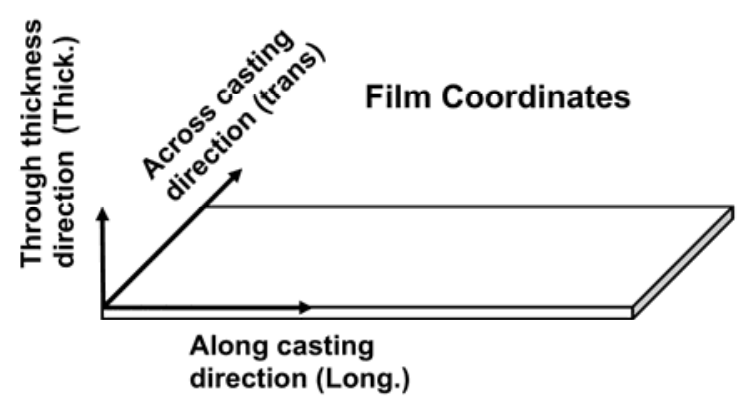

Film Preparation

a. Paint: randomly oriented particles
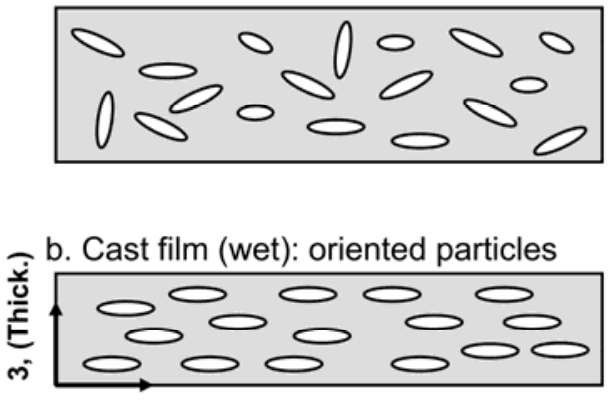

Particle Coordinates

1, (Long.)

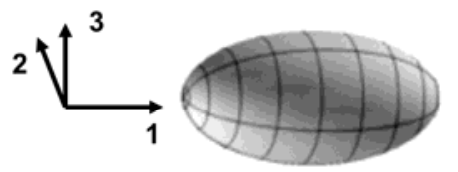

c. Cast film (dry): tilted particles

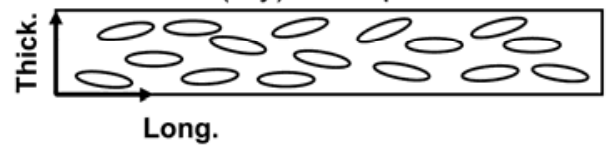

Figure 3. Proposed effect of film preparation on the orientation of $\mathrm{CaCO}_{3}$ fibres.

\subsection{Modulus Enhancement in the Glass-Transition Region}

Under ambient conditions, the stress in latex paint films is highly rate dependent due to the close proximity of the glass transition temperature $\left(10^{\circ} \mathrm{C}\right)$. This is illustrated in Figure 4 with a step relaxation experiment at $20^{\circ} \mathrm{C}$ on the non-pigmented latex. A sample was extended at $5 \mathrm{~mm} / \mathrm{min}$ to a strain of 0.02 , and then held for $10 \mathrm{~min}$ as the load was monitored. The curve shows a characteristic sharp rise in stress during the loading ramp, followed by a rapid decay over a decade interval of time. Parameters for a viscoelastic material model are given later in this section, and the continuous curve in Figure 4 illustrates the prediction for this particular strain history. Tensile data is also presented in Figure 5 for the latex films containing $25 \%$ $\mathrm{TiO}_{2}$ by volume using different test speeds and temperatures. The trends are very similar for the other films [27]; therefore, the curves are only given for one material. Small strains are of primary interest in this discussion of modulus enhancement and full stress-strain curves can be found in $[6,27]$ showing values up to 1.5 at low rates of deformation. At such high strains, the latex exhibits the characteristics of a hyperelastic material. Note that the only samples shown to failure here are the 50,5 , and $0.5 \mathrm{~mm} / \mathrm{min}$ tests at $-10^{\circ} \mathrm{C}$ in Figure $5 \mathrm{a}$. 


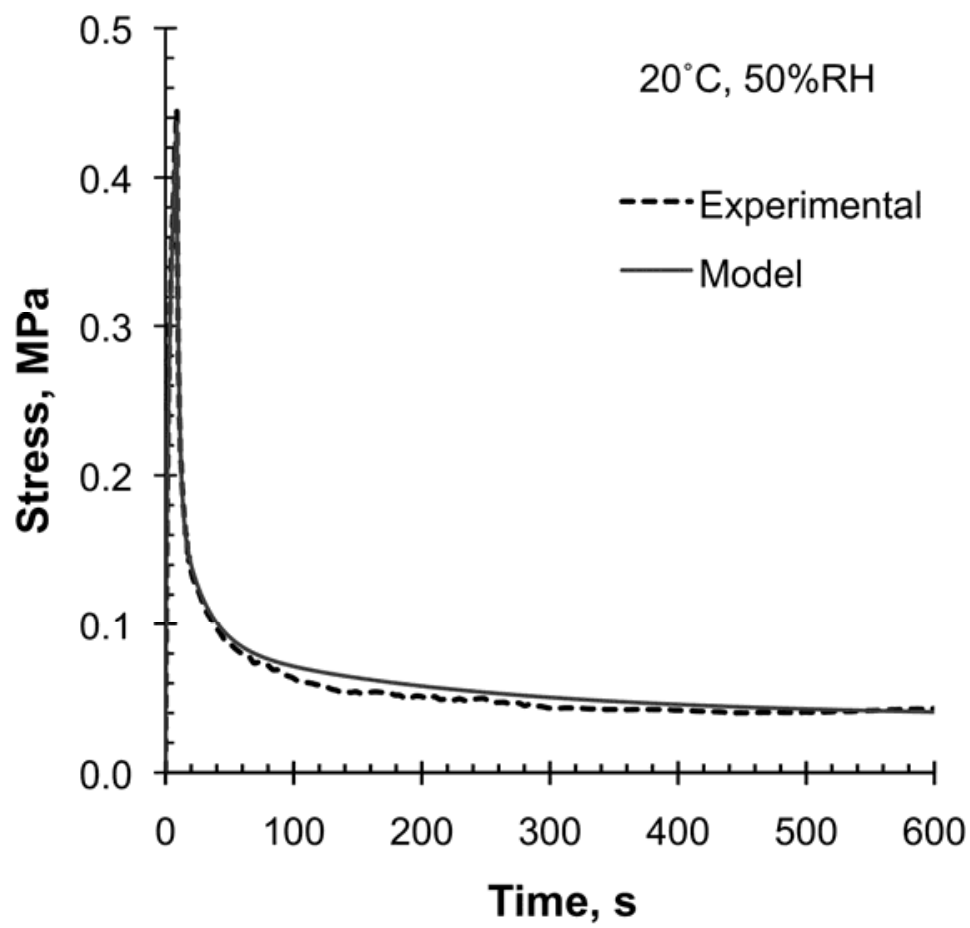

Figure 4. Stress relaxation experiment for the non-pigmented latex at $20^{\circ} \mathrm{C}, 50 \% \mathrm{RH}$ and the viscoelastic material model prediction $(5 \mathrm{~mm} / \mathrm{min}$ initial ramp to strain of 0.02$)$.

A viscoelastic material model is presented for the stress-strain data using a neo-Hookean [32] hyperelastic function in combination with a Prony series for the strain range of $0 \leq \varepsilon \leq 0.02$. The method employed is similar to that used in [33], where the Ogden model was combined with a Prony series to predict the tensile curves at large strains. For this particular model, the time-dependent true stress for an arbitrary loading history is given by the Leaderman form of the convolution integral $[34,35]$ :

$$
\sigma_{0}(\lambda, t)=\int_{0} g(t-s) \frac{\mathrm{d} \sigma_{0}(\lambda)}{\mathrm{d} s} \mathrm{~d} s
$$

where the instantaneous uni-axial stress-stretch relationship is given as:

$$
\sigma_{0}(\lambda)=\mu_{0}\left(\lambda^{2}-1 / \lambda\right)
$$

for the neo-Hookean hyperelastic function. The stretch ratio, $\lambda$, is related to true strain by $\lambda=\exp (\varepsilon)$ and $\mu_{0}$ is the initial shear modulus. The time dependent function $g(t)$ is represented by the Prony series:

$$
g(t)=g_{e}+\sum_{i=1}^{N} g_{i} \exp \left(-t / \tau_{i}\right)
$$

where $g_{e}$ and $g_{i}$ are the relative weights of the equilibrium and Maxwell elements respectively $\left(g_{e}=\mu_{e} / \mu_{0}\right.$, and $\left.g_{i}=\mu_{i} / \mu_{0}\right)$ and $N$ is the number of elements in the series. Also note that $g_{e}+\sum_{i=1}^{N} g_{i}=1$. 

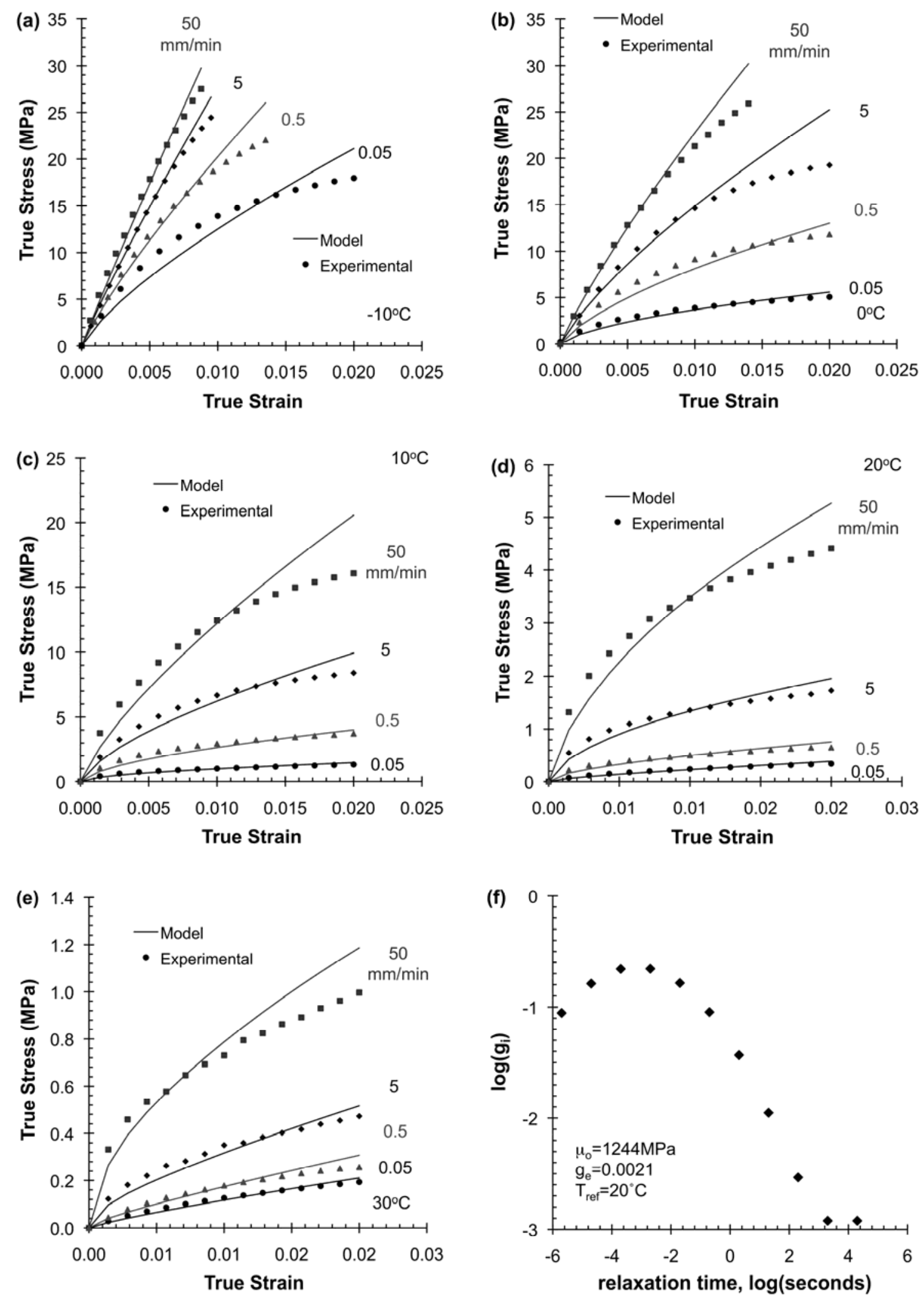

Figure 5. Stress-strain data with viscoelastic model fits for $25 \% \mathrm{TiO}_{2} \mathrm{v} / \mathrm{v}$ at four crosshead speeds and five temperatures: a. $-10^{\circ} \mathrm{C} ;$ b. $0^{\circ} \mathrm{C} ;$ c. $10^{\circ} \mathrm{C} ;$ d. $20^{\circ} \mathrm{C} ;$ e. $30^{\circ} \mathrm{C}$; f. Prony series.

The time-temperature superposition (TTS) principle was used [36, 37] to account for the effect of temperature on the relaxation spectrum. The relaxation times at a given temperature were calculated from the shift factor, $a_{T}$, and the relaxation times, $\tau_{i}^{r e f}$, at a selected reference temperature, $T_{r e f}$, according to 


$$
\tau_{i}=a_{T} \tau_{i}^{r e f}
$$

The $g_{\mathrm{i}}$ terms and $g_{\mathrm{e}}$ are not altered with temperature, only their corresponding relaxation times are modified according to Equation 14. The shift factor, $a_{T}$, values are shown as a function of temperature in Figure 6 for all samples. These were determined experimentally by shifting the plots of secant modulus versus initial strain rate (calculated as speed/gauge length) obtained at different temperatures, until a smooth master curve was created. It was found that the shift factors remained applicable at large deformations, and failure strain master-curves were also generated using the same $a_{T}$ values $[6,33]$. Figure 7 shows an isometric plot of tensile data reduced to $20^{\circ} \mathrm{C}$ for the non-pigmented latex using experiments similar to those highlighted in Figure 5 for $25 \% \mathrm{TiO}_{2}$. The parallel curves indicate that stress is a separable function of strain and time, which justifies the use of a simplified material model applied in this study. The model does fail where an instability occurs at strains above $\sim 0.025$ at short times (noted by the region of overlapping curves). A thermodynamic-based material model, such as that described by Caruthers [38], might capture this response.

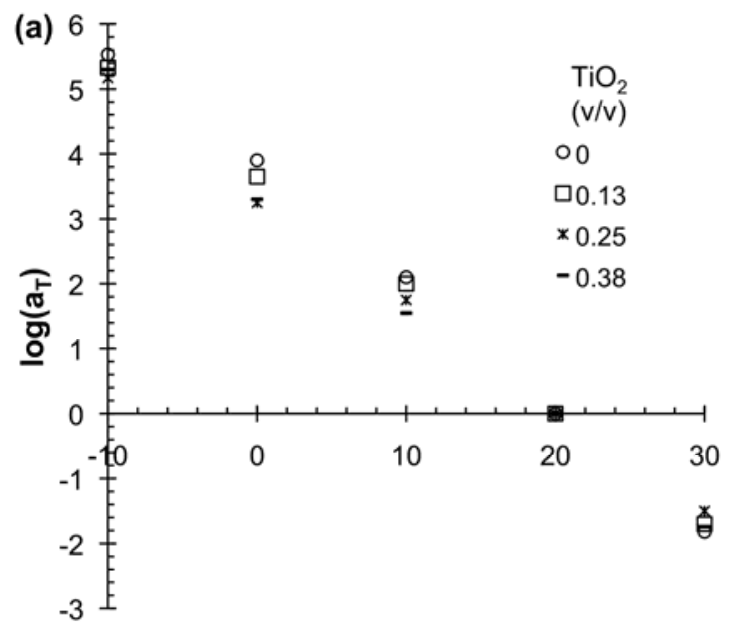

Temperature, ${ }^{\circ} \mathrm{C}$

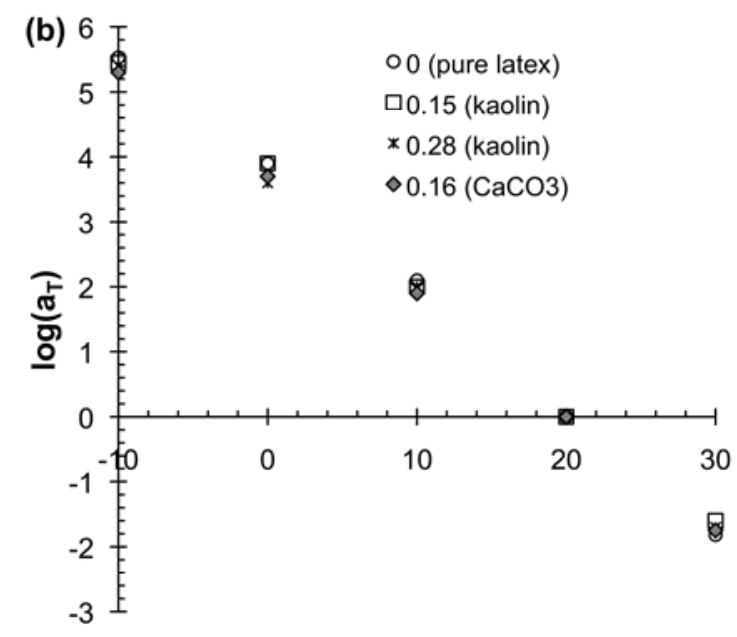

Temperature, ${ }^{\circ} \mathrm{C}$

Figure 6. Shift factors from TTS at $T_{r e f}=20^{\circ} \mathrm{C}$ : a. $\mathrm{TiO}_{2} ;$ b. kaolin and $\mathrm{CaCo}_{3}$ data. 


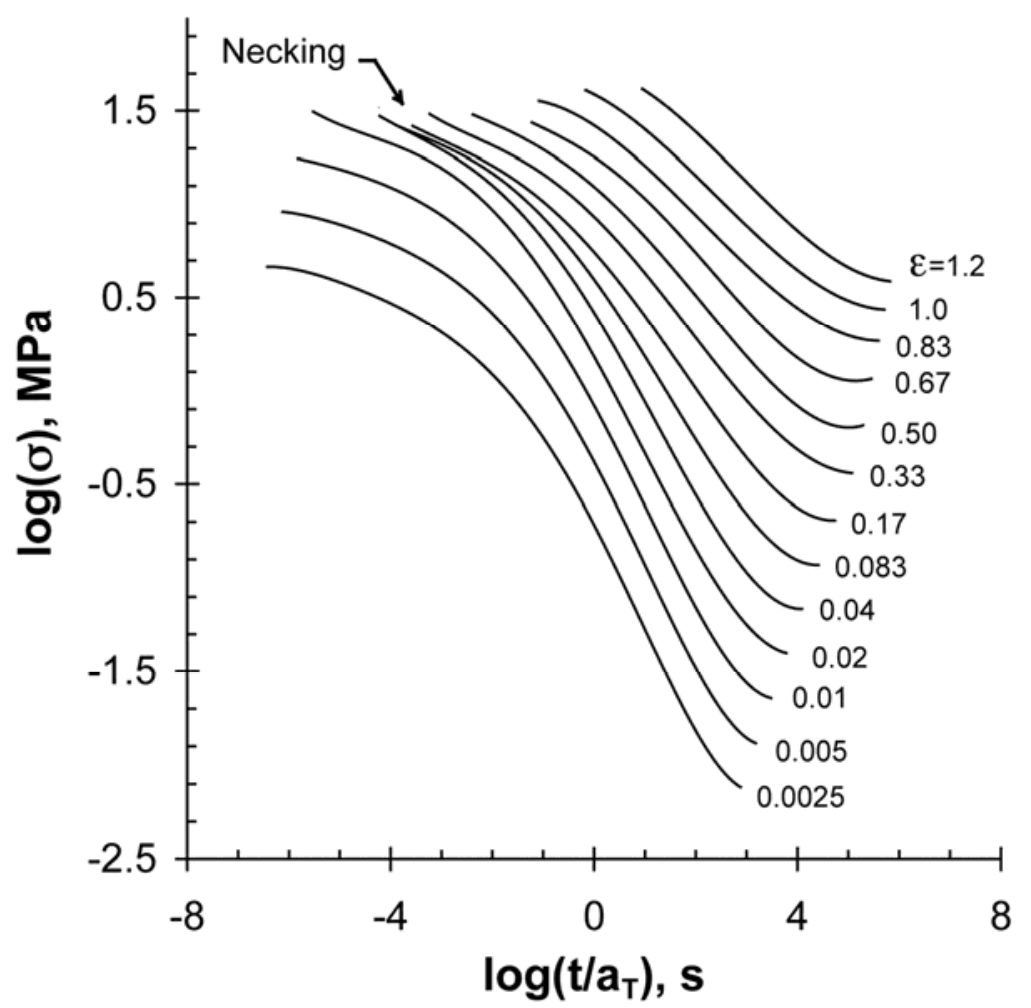

Figure 7. Isometric plot for the non-pigmented latex reduced to $20^{\circ} \mathrm{C}$ using shift factors from Figure 6 at various strain levels.

A numerical approximation method based on the finite time increment formulation of the convolution integral in Equation 11 was used [35] to derive an analytical expression for the stress at any time and corresponding strain. This allowed the model to be calibrated using the experimental data and the Solver optimization tool from Lumina Systems. The best-fit material parameters are shown in Table 2 for all films. Calculated values of RMSE (root mean squared error) are also given in Table 2 in order to compare the accuracy of fit for each set of data. The model fit can be seen in Figure 4 for the relaxation test on the non-pigmented latex, and in Figure 5a-e for stress-strain curves on the $25 \% \mathrm{TiO}_{2}$ material. The agreement is reasonable considering that the model has to fit data obtained over a very broad time scale and range of temperatures. Figure $5 \mathrm{f}$ shows the non-dimensional Prony series weights versus $\log$ (time) as a smooth bell-shaped curve. The results were obtained by initially constraining the Solver algorithm such that the $g_{i}$ terms would fit to a Gaussian distribution function.

Table 2. Prony series and neo-Hookean parameters for the viscoelastic material models.

\begin{tabular}{|c|c|c|c|c|c|c|c|c|}
\hline Element i & Relax Time $\tau_{i}, \mathrm{~s}$ & Latex Binder $g_{i}$ & $13 \% \mathrm{TiO}_{2} g_{i}$ & $25 \% \mathrm{TiO}_{2} g_{i}$ & $38 \% \mathrm{TiO}_{2} g_{i}$ & $16 \% \mathrm{CaCO}_{3} g_{i}$ & $14 \%$ Kaolin $g_{i}$ & $28 \%$ Kaolin $g_{i}$ \\
\hline 1 & $2 . E-06$ & $1.09 \mathrm{E}-01$ & $6.56 \mathrm{E}-02$ & $8.86 \mathrm{E}-02$ & $9.54 \mathrm{E}-02$ & $6.07 \mathrm{E}-02$ & $2.30 \mathrm{E}-01$ & $1.23 \mathrm{E}-01$ \\
\hline 2 & 2.E -05 & $1.86 \mathrm{E}-01$ & $1.42 \mathrm{E}-01$ & $1.62 \mathrm{E}-01$ & $1.66 \mathrm{E}-01$ & $1.31 \mathrm{E}-01$ & $2.22 \mathrm{E}-01$ & $1.84 \mathrm{E}-01$ \\
\hline 3 & 2.E -04 & $2.35 E-01$ & $2.18 \mathrm{E}-01$ & $2.20 \mathrm{E}-01$ & $2.13 E-01$ & $2.05 \mathrm{E}-01$ & $1.54 \mathrm{E}-01$ & $2.14 \mathrm{E}-01$ \\
\hline 4 & 2.E -03 & $2.17 \mathrm{E}-01$ & $2.38 \mathrm{E}-01$ & $2.20 \mathrm{E}-01$ & $2.02 \mathrm{E}-01$ & $2.32 \mathrm{E}-01$ & $1.54 \mathrm{E}-01$ & $1.96 \mathrm{E}-01$ \\
\hline 5 & $2 . E-02$ & $1.47 \mathrm{E}-01$ & $1.83 E-01$ & $1.64 \mathrm{E}-01$ & $1.42 \mathrm{E}-01$ & $1.90 \mathrm{E}-01$ & $1.26 \mathrm{E}-01$ & $1.41 \mathrm{E}-01$ \\
\hline 6 & 2.E -01 & $7.33 E-02$ & $9.99 E-02$ & $9.03 E-02$ & $7.32 \mathrm{E}-02$ & $1.12 \mathrm{E}-01$ & $6.76 \mathrm{E}-02$ & $7.90 \mathrm{E}-02$ \\
\hline 7 & $2 . \mathrm{E}+00$ & $2.68 \mathrm{E}-02$ & $3.86 \mathrm{E}-02$ & $3.68 \mathrm{E}-02$ & $2.80 \mathrm{E}-02$ & $4.79 \mathrm{E}-02$ & $3.24 \mathrm{E}-02$ & $3.48 \mathrm{E}-02$ \\
\hline 8 & $2 . \mathrm{E}+01$ & $3.57 \mathrm{E}-03$ & $1.06 \mathrm{E}-02$ & $1.11 \mathrm{E}-02$ & $2.05 E-02$ & $1.48 \mathrm{E}-02$ & $8.84 \mathrm{E}-03$ & $1.20 \mathrm{E}-02$ \\
\hline 9 & $2 . E+02$ & $1.49 \mathrm{E}-03$ & $2.05 E-03$ & $2.93 E-03$ & $4.31 \mathrm{E}-03$ & $3.30 \mathrm{E}-03$ & $2.23 E-03$ & $3.25 E-03$ \\
\hline 10 & $2 . E+03$ & $2.73 E-04$ & $5.41 \mathrm{E}-04$ & $1.20 \mathrm{E}-03$ & $4.07 \mathrm{E}-03$ & $9.53 E-04$ & $5.55 E-04$ & $3.25 E-03$ \\
\hline 11 & $2 . E+04$ & $2.73 E-04$ & $5.41 \mathrm{E}-04$ & $1.20 \mathrm{E}-03$ & $0.00 \mathrm{E}+00$ & $9.53 E-04$ & $5.55 E-04$ & $3.25 E-03$ \\
\hline e $\left(g_{e}\right)$ & - & $7.11 \mathrm{E}-04$ & $1.12 \mathrm{E}-03$ & $2.09 E-03$ & $1.14 \mathrm{E}-02$ & $1.17 \mathrm{E}-03$ & $1.56 \mathrm{E}-03$ & $6.27 E-03$ \\
\hline$\mu_{o}(\mathrm{MPa})$ & & 577 & 783 & 1244 & 1744 & 941 & 1254 & 1786 \\
\hline RMSE & & 0.066 & 0.093 & 0.11 & 0.17 & 0.10 & 0.13 & 0.16 \\
\hline
\end{tabular}

The micromechanics theory for a composite with elastic phases remains applicable for a viscoelastic matrix by means of the correspondence principle. This rule states that the equations for the elastic solution are directly valid in the Carson ( $z$-multiplied Laplace) 
transformed domain [39]. The calculations are performed as before; however, it becomes necessary to determine the inverse Laplace transform to obtain the time-domain solution. Wang and Weng [40] provide Mori-Tanaka solutions in the transformed domain to parallel the work with elastic composites. Clements and Mas [41, 42] have simplified this theory in order to obtain convenient solutions in the time-domain that are easily applied without the need for numerical approximation methods. The equations of Clements and Mas are briefly outlined below since their theory will be adapted to our work and compared with tensile data from the latex films.

Clements and Mas [41, 42] derived expressions for the bulk and shear moduli of viscoelastic composites with randomly oriented and aligned particles. They simplified the results of Wang and Weng [40] by noting that $\mu^{m}(t)<<K^{m}$ holds above the glass transition. The bulk modulus of the matrix was assumed to be rate independent since it varies much less with time than the other moduli. They expanded the composite stress relaxation functions as a Taylor series about $\mu^{m}(t) / K^{m}$ since this ratio is small for rubbery materials. This allowed for an analytical inverse Laplace transformation and the stress relaxation function of the composite was then derived as a time-domain Prony series. Their results for the bulk and shear moduli in the case of $3 \mathrm{D}$ random particle orientation are

$$
\begin{aligned}
& K^{*}(t)=\frac{K^{m} K^{f}}{c^{f} K^{m}+c^{m} K^{f}}+\left\lfloor\frac{c^{f} c^{m}\left(K^{f}-K^{m}\right)^{2} G_{1}}{9\left(c^{f} K^{m}+c^{m} K^{f}\right)^{2}}\right\rfloor \mu^{m}(t) \\
& \mu^{*}(t)=\left(1+\frac{4 c^{f}}{5 c^{m}} G_{2}\right) \mu^{m}(t)
\end{aligned}
$$

where

$$
\begin{aligned}
& G_{1}=\frac{16-\beta^{2}\left(8-3 I_{0}\right)^{2}-12 I_{0}+9 I_{0}^{2}}{2 \beta^{2}\left(I_{0}-2\right)+I_{0}} \\
& G_{2}=\left(\beta^{2}-1\right)\left[\frac{-2}{\left(\beta^{2}+1\right)\left(4-3 I_{0}\right)}+\frac{4}{\left(4 \beta^{2}-3 I_{0}\right)}+\frac{1}{3\left(4 \beta^{2}-\left(1+2 \beta^{2}\right) I_{0}\right)}\right] \\
& I_{0}=\left\{\begin{array}{l}
\frac{2 \beta}{\left(\beta^{2}-1\right)^{3 / 2}}\left[\beta\left(\beta^{2}-1\right)^{1 / 2}-\cosh ^{-1}(\beta)\right] \beta \geq 1 \\
\frac{2 \beta}{\left(1-\beta^{2}\right)^{3 / 2}}\left[\cosh ^{-1}(\beta)-\beta\left(1-\beta^{2}\right)^{1 / 2}\right] \beta \leq 1
\end{array}\right.
\end{aligned}
$$

The parameter $\mu^{\mathrm{m}}(t)$ is the time-dependent shear modulus of the matrix, which can be defined by a Prony series

$$
\mu^{m}(t)=\mu_{0}^{m} g^{m}(t)=\mu_{0}^{m} g_{e}+\sum_{i=1}^{N} \mu_{0}^{m} g_{i}^{m} \exp \left(-t / \tau_{i}\right) .
$$

Figure 8a shows several shear relaxation functions plotted from Equations 16 and 19. The curves were calculated by setting $\mu_{0}{ }^{m}, g_{\mathrm{i}}{ }^{m}$, and $g_{\mathrm{e}}{ }^{m}$ equal to the constants listed for the latex binder in Table 2 . The time-dependent $\mu(t)$ curves are given versus $\log ($ time $)$ for the various volume fractions of $\mathrm{TiO}_{2}$. Figure $8 \mathrm{~b}$ shows the curves calculated using the constants in Table 2 for each $\mathrm{TiO}_{2}$ volume fraction. Recall that these were the values that resulted from the best 
fit of the viscoelastic model to the experimental data. There are obvious differences in Figures $8 \mathrm{a}$ and $8 \mathrm{~b}$, with the latter showing a much stronger enhancement at long times in the rubbery region. In Figure 9, the shear relaxation curves from the Clements-Mas theory $(\beta=0.1,3 \mathrm{D}$ random) are also given with those calculated using the parameters in Table 2 for films with kaolin. A comparison of the two graphs once again shows a stronger enhancement in the rubbery region than the micromechanics theory predicts. Curves for films containing $\mathrm{TiO}_{2}$ and $\mathrm{CaCO}_{3}$ are included in Figure $9 \mathrm{~b}$ for comparison using the determined material parameters. It is interesting to note that the curves for 0.28 kaolin and $0.38 \mathrm{TiO}_{2}$ are very similar through the entire time-scale.

(a)

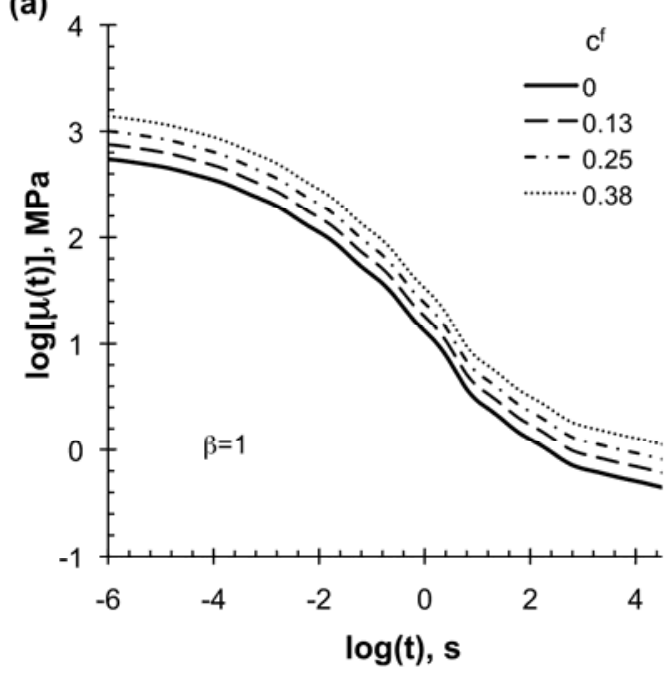

(b)

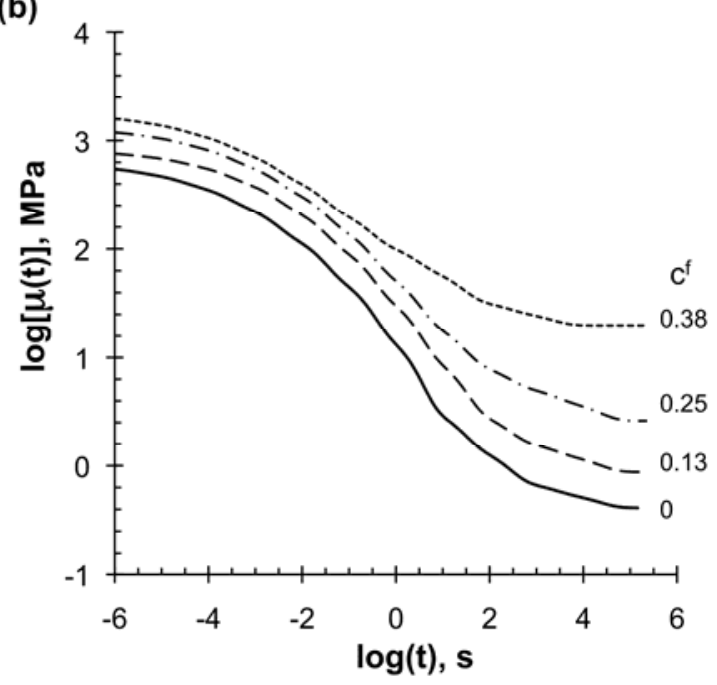

Figure 8. Shear relaxation function curves at $T_{r e f}=20^{\circ} \mathrm{C}$ : a. Clements-Mas theory for a viscoelastic matrix filled with spherical particles; $b$. Viscoelastic material model results using Table 2 parameters for latex films containing $\mathrm{TiO}_{2}$.

(a)

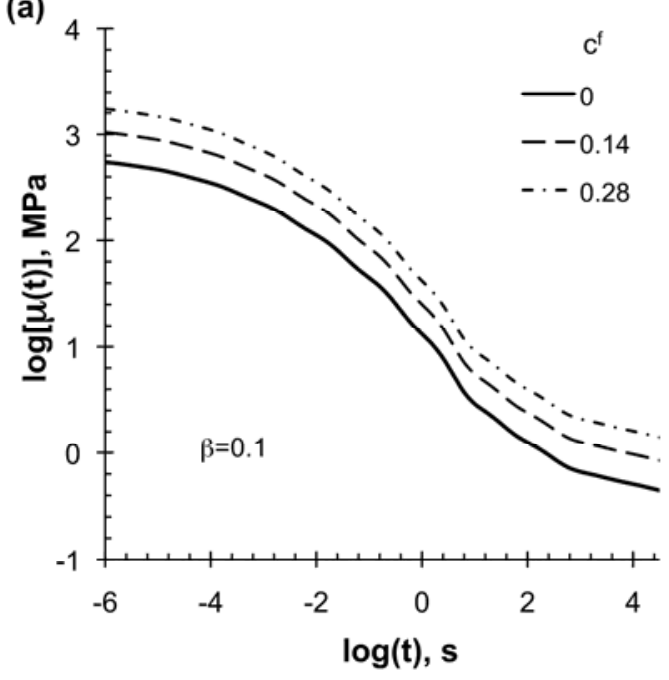

(b)

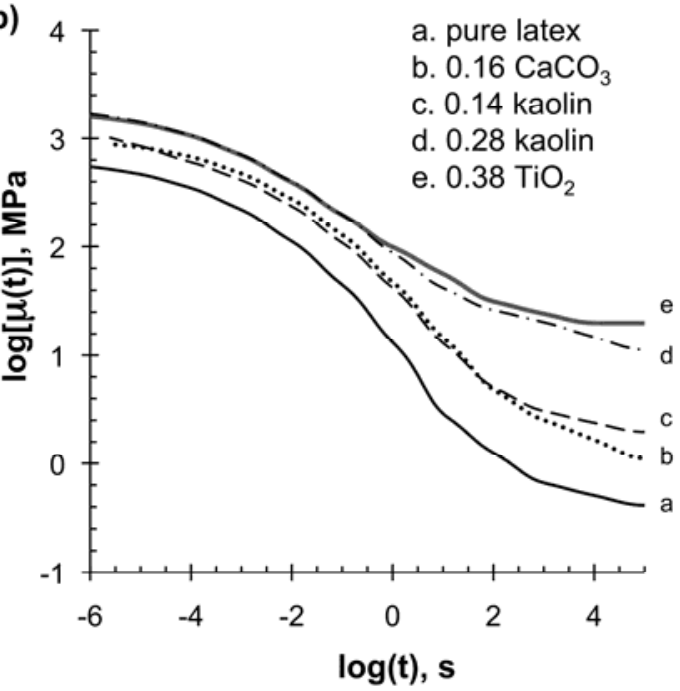

Figure 9. Shear relaxation curves at $T_{r e f}=20^{\circ} \mathrm{C}$ : a. Clements-Mas theory for a viscoelastic matrix filled with particles having $\beta=0.1 ; \mathrm{b}$. Viscoelastic material model results using Table 2 parameters for latex films containing kaolin $\left(\mathrm{CaCO}_{3}\right.$ data also shown).

A similarly strong modulus enhancement for filled polymers, especially in the rubbery region, has also been reported by other researchers [43-46]. There are several possible reasons for the discrepancy. One explanation is that the small size of the $\mathrm{TiO}_{2}$ particles offers a large specific surface area (surface area/volume) with a significant fraction of the polymer forming a 
constrained glassy layer at the interface. Figure 10a compares the modulus enhancement in the rubbery region with the Leilens micromechanics predictions. The data points are also recalculated to include an effective volume fraction generated by a $52 \mathrm{~nm}$ rigid (glassy) layer of polymer on the surface. This new data appears to match the model; however, DSC experiments did not show a $T_{g}$ increase with pigment content [6]. A more likely cause is the formation of an enhanced network within the matrix that results from the relatively small $\mathrm{TiO}_{2}$ particle size and the high MW $\left(\sim 10^{6} \mathrm{~g} / \mathrm{mol}\right)$ of the copolymer. Hahn [47] reported radius of gyration, $R_{g}$, values up to $96 \mathrm{~nm}$ for a poly $(n \mathrm{BMA})$ latex $(\mathrm{MW}=500,000 \mathrm{~g} / \mathrm{mol})$ heated above its $T_{g}$. To gain a sense of scale, consider the mean spacing, $l$, between spherical particles of diameter, $D[48]$ :

$$
l=D\left\lfloor\left(\frac{\phi_{m}}{c^{f}}\right)^{1 / 3}-1\right\rfloor
$$

Random close packing gives $\phi_{m}=0.64$; therefore, a $\mathrm{TiO}_{2}$ volume concentration of 0.25 with $D=300 \mathrm{~nm}$ results in a spacing of $l=110 \mathrm{~nm}$. At $c^{f}=0.38$, the spacing becomes $l=57 \mathrm{~nm}$. Bridging of molecules between adjacent $\mathrm{TiO}_{2}$ particles becomes increasingly likely as the pigment volume fraction increases to moderate levels. This could lead to a highly enhanced modulus in the terminal region with minimal effect on the $T_{g}$.

It is also possible that the inorganic particles form a percolation network [49, 50]. Figure 10b shows a semi-log plot of the experimental Young's modulus and theoretical equilibrium shear modulus (from the model parameters in Table 2) versus $\mathrm{TiO}_{2}$ volume fraction. Potanin et al [50] provide general equations for aggregated dispersions. Assuming a network of random chains, their results provide a simplified proportionality between moduli values and particle concentration:

$$
E^{*}, \mu^{*} \propto\left(c^{f}\right)^{4 /\left(3-d_{f}\right)}
$$

where $d_{f}$ is the fractal dimension. It is apparent from Equation 21 that the slope of the lines in Figure $10 \mathrm{~b}$ is equal to $4 /\left(3-d_{f}\right)$. Rearranging gives $d_{f}=2.37$ for the experimental $E^{*}$ data, and $d_{f}=2.26$ using the derived model $\mu_{e}{ }^{*}$ parameters. Both are quite close to the percolation cluster value of $d_{f}=2.5$.
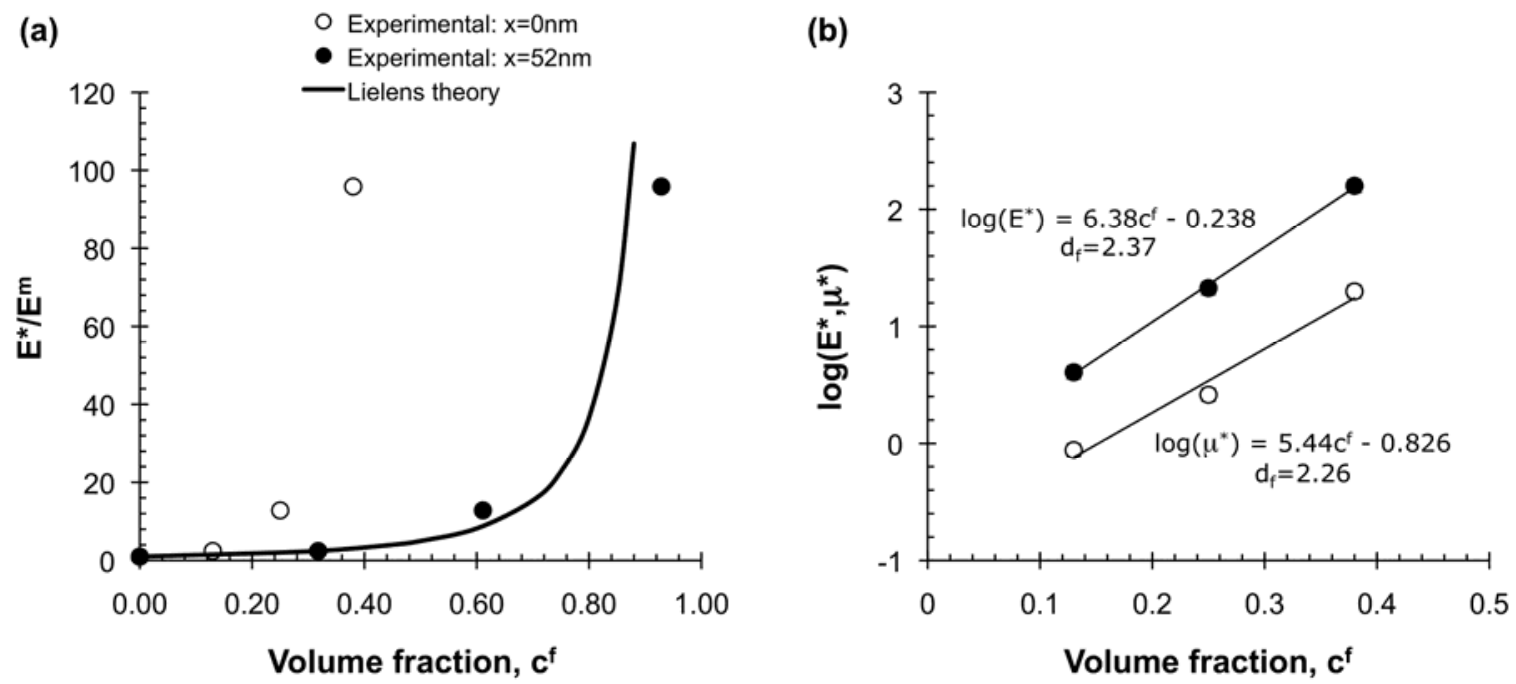

Figure 10. Rubbery modulus enhancement: a. constrained matrix with glassy shell thickness $x=0$ and 
$x=52 \mathrm{~nm}$ plotted with Lielens theory and experimental $E^{*}\left(30^{\circ} \mathrm{C}, 0.05 \mathrm{~mm} / \mathrm{min}\right)$; b. percolation theory showing $\log \left(E^{*}\right)$ (experimental) and $\log \left(\mu_{e}^{*}\right)$ (material model in Table 2).

Figure 11 further illustrates the results from the viscoelastic material model in relation to micromechanics predictions. The initial modulus enhancement $\left(\mu_{o}{ }^{*} / \mu_{o}{ }^{m}\right)$ is given in Figure 11a along with the elastic Mori-Tanaka and Lielens theories calculated for spherical $\mathrm{TiO}_{2}$ particles in the latex matrix (using $v^{m}=0.499$ ). Curves are also plotted using the modified equation that Clements and Mas propose for shear modulus

$$
\mu^{*}(t)=\left(1+\frac{4 c^{f}}{5\left(1-f_{c} c^{f}\right)} G_{2}\right) \mu^{m}(t)
$$

in which an enhancement parameter, $f_{c}$, is added. A value of $f_{c}=1$ gives the standard MoriTanaka result, while larger values account for higher-order filler interactions. In agreement with the earlier discussion, the predictions are reasonable since the initial shear modulus dominates in the glassy regime. The equilibrium element enhancement

$$
\frac{\mu_{e}^{*}}{\mu_{e}^{m}}=\frac{\mu_{o}^{*} g_{e}^{*}}{\mu_{o}^{m} g_{e}^{m}}
$$

is plotted in Figure $11 \mathrm{~b}$ together with the initial modulus enhancement for comparison purposes. It is apparent that the equilibrium enhancement is dramatically stronger than the initial one. For this reason, it is not possible for the micromechanics model to capture the behaviour in the rubbery regime where the equilibrium modulus dominates.
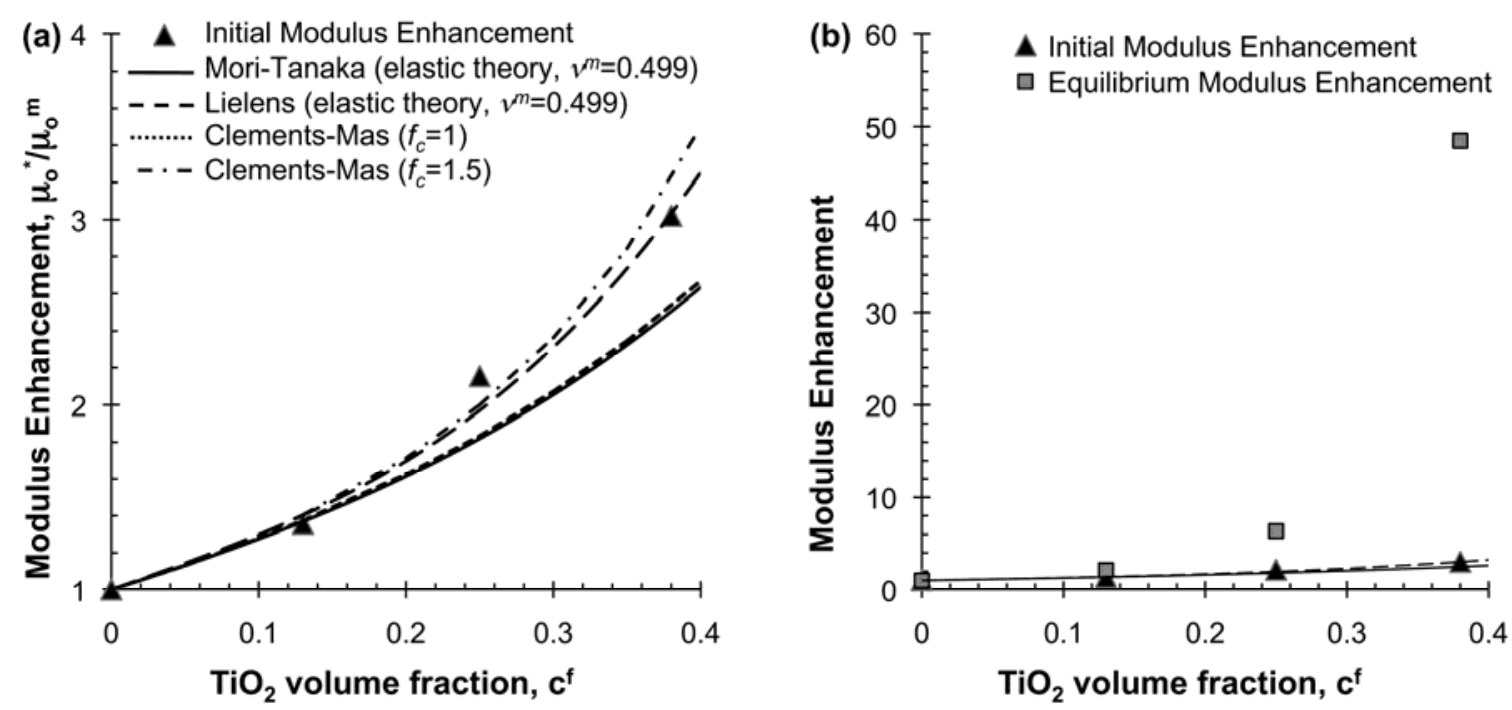

Figure 11. a. Initial modulus enhancement comparing Table 2 data with Mori-Tanaka, Lielens and Clements-Mas models; b. Comparison of initial and equilibrium modulus (Equation 22) enhancements from Table 2 values.

\subsection{Dynamic Mechanical Analysis}

Dynamic testing was also performed on the $\mathrm{TiO}_{2}$ pigmented paint films at an increased age of four years. These measurements were obtained using temperature sweeps from $-30^{\circ} \mathrm{C}$ to $100^{\circ} \mathrm{C}$ with dynamic strain applied at a constant frequency of $1 \mathrm{~Hz}$. Humidity control was not provided by the instrument, and the moisture content in the samples was lower due to a 
laboratory $\mathrm{RH}$ of $30 \%$. It is possible to compare several trends in these data with the previously described tensile results. Slight differences in the magnidudes and shapes of the curves are expected (in relation to the monotonic experiments) as a result of the increased age and lower moisture content. The results are, however, quite complementary.

The dynamic data are shown in Figure 12a-c for the storage modulus, loss modulus, and loss tangent respectively. Storage modulus curves highlight the transition from glassy to rubbery regimes as temperature is raised, and the overall increase in magnitude as more pigment is added. The elevated modulus in the terminal region is accompanied by an extension to longer times. This is attributed to the additional trapped entanglements caused by adhesion of the copolymer over the $\mathrm{TiO}_{2}$ particle surfaces. Mortezai et al [51] observed a strong shift of the loss tangent peaks when a glassy layer was present on the filler particles in a polymer matrix. In the current work, the loss tangent did not change with $\mathrm{TiO}_{2}$ content for the latex paint films, which further invalidates the possibility of a glassy polymer layer in this study. The immobilised layer concept and its consequent influence on viscoelasticity of filled polymers has previously been disputed by Song et al. [46] and Robertson et al. [52]. It is also noted that the glass-transition temperature is frequently taken from the peak of the loss modulus for filled polymers [52], and the values of $16^{\circ} \mathrm{C}$ to $18^{\circ} \mathrm{C}$ in Figure $12 \mathrm{~b}$ are slightly higher than that measured by differential scanning calorimetry (DSC) for these films [6]. The loss tangent peak is commony much higher as described in [53], and the values in Figure $12 \mathrm{c}$ are at $\sim 40^{\circ} \mathrm{C}$. A higher $T_{g}$ is typical with DMA data, and DSC is known as the the more standard method for defining this parameter [53]. 

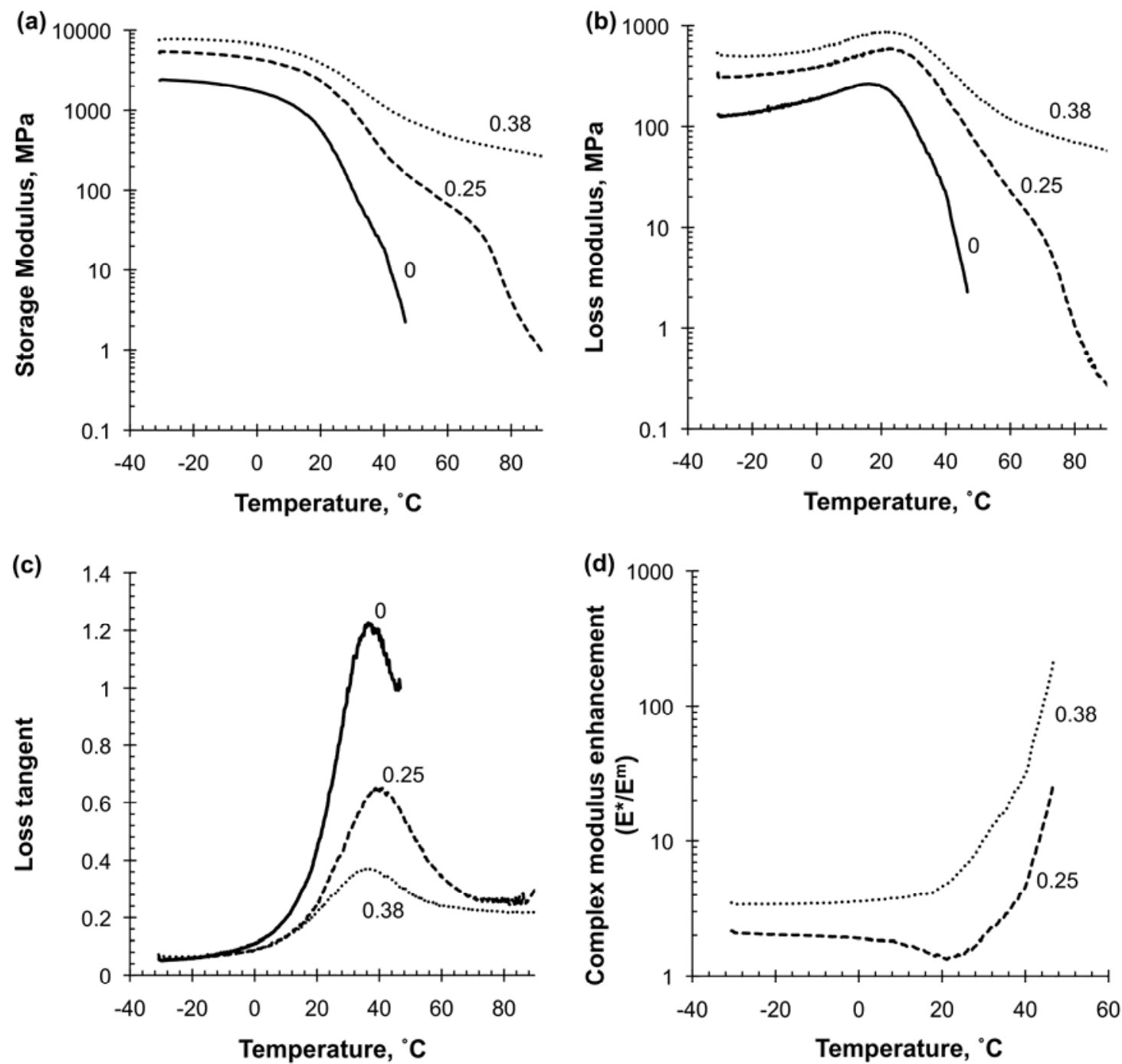

Figure 12. DMA results from temperature sweeps at 1Hz: a. Storage modulus; b. Loss modulus; c. Loss tangent; $d$. Complex modulus enhancement.

The complex modulus was also calculated from the storage and loss moduli. This was used to plot the modulus enhancement at 0.25 and $0.38 \mathrm{TiO}_{2}$ as a function of temperature in Figure $12 \mathrm{~d}$. The lowest enhancement occurs in the glassy region with values similar to those given in Figure $2 \mathrm{~b}$. The sharp increase above $T_{g}$ also confirms the strong enhancement in the rubbery region that was indicated previously in Figure 10a.

\section{Conclusions}

The effects of particle volume fraction and geometry were highlighted for the tensile behaviour of latex paint films as measured from monotonic tensile tests and DMA experiments. Young's modulus data in the glassy region showed good agreement with micromechanics theories, and the Lielens method was found especially accurate for films made with three different fillers. As expected, the lowest enhancement of Young's modulus was given by the $\mathrm{TiO}_{2}$ particles since they were nearly spherical. Higher values were given by films with $\mathrm{CaCO}_{3}$ when tested parallel to the casting direction; however, in the tranverse direction these films were similar to those containing $\mathrm{TiO}_{2}$. The strongest enhancement was observed with films containing kaolin that were tested along the casting direction. 
Viscoelastic material models were fitted to tensile data in order to capture the response across the glass-transition region. The models fit well for low strains $(0<\varepsilon<0.02)$ up to a relatively high volume fraction of $0.38 \mathrm{TiO}_{2}$. Time-dependent shear modulus curves were plotted using the parameters determined from the viscoelastic model calibrations, and these were compared with the Clements-Mas equations for the Mori-Tanaka theory in the time-domain. In accordance with other published literature, the experimental results showed a much higher modulus in the rubbery region than predicted by the theoretical equations. This may have resulted from the small $\mathrm{TiO}_{2}$ particle size and the formation of an enhanced network within the high MW copolymer matrix. In addition, a derived fractal dimension of $d_{f} \approx 2.3-2.4$ provided an indication that percolation may have contributed to the strong modulus enhancement.

\section{Acknowledgements}

The authors would like to thank the Deborah Loeb Brice Foundation and the Natural Sciences and Engineering Research Council of Canada (NSERC) for funding this project, and Golden Artist Colors for providing the custom paint formulations. We also greatly appreciate the advice offered by Dr. Brad Clements at Los Alamos National Laboratory, Dr. Andrei Potanin at Colgate Palmolive, and Prof. Stuart Croll at North Dakota State University. Finally, we would like to thank Dr. Jinqgi Cai from Imperial College London for performing the DMA experiments.

\section{References}

1. H. Warson and C.A. Finch. Latices in Surface Coatings: Emulsion Paints. John Wiley \& Sons, Chichester, (2001).

2. T.J.S. Learner. Analysis of Modern Paints. Getty Conservation Instutute, Los Angeles, (2005).

3. J. Hayes. Personal Communication. (2011).

4. J.L. Keddie. Materials Science and Engineering: R Reports 21(1997), pp. 101-170.

5. P.A. Steward, J. Hearn, and M.C. Wilkinson. Advances in Colloid and Interface Science 86(2000), pp. 195267.

6. E.W.S. Hagan, M.N. Charalambides, C.R.T. Young, T.J.S. Learner, and S. Hackney. Progress in Organic Coatings 69(1) (2010), pp. 73-81.

7. H.A. Oosterhof. Journal of the Oil \& Colour Chemists' Association 48(1965), pp. 256-279.

8. C. Bondy and M.M. Coleman. Journal of the Oil \& Colour Chemists' Association 53(1970), pp. 555-577.

9. N. Agarwal and R.J. Farris. Journal of Applied Polymer Science 72(11) (1999), pp. 1407-1420.

10. N. Agarwal and R.J. Farris. Polymer Engineering and Science 40(2) (2000), pp. 376-390.

11. J.D. Erlebacher, M.F. Mecklenburg, and S.J. Tuman. Polymer Preprints 33(2) (1992), pp. 646-647.

12. M.F. Mecklenburg, C.S. Tumosa, and J.D. Erlebacher. Polymer Preprints 35(2) (1994), pp. 297-298.

13. E. Hagan and A. Murray. Materials Research Society Symposium Proceedings 852(2005), pp. 41-48. 
14. C.L.I. Tucker and E. Liang. Composites Science and Technology 59(1999), pp. 655-671.

15. R. Hill. Journal of the Mechanics and Physics of Solids 13(4) (1965), pp. 213.

16. T. Mori and K. Tanaka. Acta Metallurgica 21(1973), pp. 571-574.

17. G.P. Tandon and G.J. Weng. Composites science and technology 27(1986), pp. 111-132.

18. G.P. Tandon and G.J. Weng. Polymer Composites 5(1984), pp. 327-333.

19. J.D. Eshelby. Proceedings of the Royal Society of London. Series A, Mathematical and Physical Sciences 252(1271) (1959), pp. 561-569.

20. J.D. Eshelby. Proceedings of the Royal Society of London. Series A, Mathematical and Physical Sciences 241(1226) (1957), pp. 376-396.

21. G. Lielens, P. Pirotte, A. Couniot, F. Dupret, and R. Keunings. Composites Part A 29A(1998), pp. 63-70.

22. M. van Es. Polymer-clay nanocomposites: the importance of particle dimensions. Polymer Materials and Engineering, PhD. Delft: Delft University of Technology, PhD Thesis (2001).

23. J.C. Halpin and J.L. Kardos. Polymer Engineering and Science 16(5) (1976), pp. 344-352.

24. J.C. Halpin. Journal of Composite Materials 3(1969), pp. 732-735.

25. L.E. Nielsen. Journal of Applied Physics 41(1970), pp. 4626.

26. L.E. Nielsen and R.F. Landel. Mechanical Properties of Polymers and Composites, 2nd ed. Marcel Dekker, New York, (1994).

27. E.W.S. Hagan. The viscoelastic properties of latex artist paints. Department of Mechanical Engineering, Ph.D. London, UK: Ph.D. thesis, Imperial College London (2009).

28. Z. Wang, H. Wang, and M.E. Cates. Geophysics 66(2) (2001), pp. 428-440.

29. J.D. Bass. Elasticity of Minerals, Glasses, and Melts. In: Ahrens TJ, editor. Mineral Physics and Crystallography: A Handbook of Physical Constants, American Geophysical Union, Washington, D.C. (1995).

30. N.W. Tschoegl, W.G. Knauss, and I. Emri. Mechanics of Time-Dependent Materials 6(1) (2002), pp. 41.

31. O.A. Stapountzi, M.N. Charalambides, and J.G. Williams. Composites Science and Technology 69(2009), pp. 2015-2023.

32. L.R.G. Treloar, H.G. Hopkins, R.S. Rivlin, and J.M. Ball. Proceedings of the Royal Society of London. Series A, Mathematical and Physical Sciences 351(1666) (1976), pp. 301-330.

33. E.W.S. Hagan, M.N. Charalambides, C.R.T. Young, T.J.S. Learner, and S. Hackney. Mechanics of TimeDependent Materials 13(2) (2009), pp. 149-161.

34. H. Leaderman. Elastic and creep properties of filamentous materials and other high polymers. The Textile Foundation, Washington, D.C., (1943).

35. S.M. Goh, M.N. Charalambides, and J.G. Williams. Mechanics of Time-Dependent Materials 8(2004), pp. $255-268$

36. Y.S. Urzhumtsev. Mechanics of Composite Materials 11(1) (1975), pp. 57-71.

37. J.D. Ferry. Viscoelastic Properties of Polymers, 3rd ed. Wiley, New York, (1980). 
38. J.M. Caruthers, D.B. Adolf, R.S. Chambers, and P. Shrikhande. Polymer 45(2004), pp. 4577-4597.

39. J.G. Williams. Stress Analysis of Polymers, 2nd ed. Halsted Press, New York, (1980).

40. Y.M. Wang and G.J. Weng. Journal of Applied Mechanics 59(1992), pp. 510-518.

41. E.M. Mas and B.E. Clements. Journal of Applied Physics 90(11) (2001), pp. 5535-5541.

42. B.E. Clements and E.M. Mas. Journal of Applied Physics 90(11) (2001), pp. 5522-5534.

43. V. Favier, G.R. Canova, J.Y. Cavaille, H. Chanzy, A. Dufresne, and C. Gauthier. Polymers for advanced technologies 6(1995), pp. 351-355.

44. V. Favier, H. Chanzy, and J.Y. Cavaille. Macromolecules 28(18) (1995), pp. 6365-6367.

45. A. Zosel. Progress in Organic Coatings 8(1980), pp. 47-79.

46. Y. Song, Q. Zheng, and Q. Cao. Journal of Rheology 53(6) (2009), pp. 1379-1388.

47. K. Hahn, G. Ley, H. Schuller, and R. Oberthur. Colloid \& Polymer Science 264(12) (1986), pp. 1092-1096.

48. T. Cosgrove. Colloid Science Principles, Methods

and Applications, 2nd ed. Wiley, UK, (2010).

49. R. Quiao and L.C. Brinson. Composites Science and Technology 69(2009), pp. 491-499.

50. A.A. Potanin, R. De Rooij, D. van den Ende, and J. Mellema. Journal of Chemical Physics 102(1995), pp. 5845-5854.

51. M. Mortezaei, G. Farzi, M.R. Kalaee, and M. Zabihpoor. Journal of Applied Polymer Science 119(4) 20392047.

52. C.G. Robertson, C.J. Lin, M. Rackaitis, and C.M. Roland. Macromolecules 41(7) (2008), pp. 2727-2731.

53. B. Bilyeu, W. Brostow, and K.P. Menard. Polymer Composites 23(6) (2002), pp. 1111-1119. 